\title{
Evaluate effectiveness of lecture cum demonstration on knowledge and skill regarding cranial nerve assessment among B.Sc. nursing students
}

\author{
Aparna Pandey ${ }^{1}$, Vijaya Kumar $\mathbf{S}^{2, *}$ \\ ${ }^{1}$ PhD Scholar, ${ }^{2}$ Professor, ${ }^{1}$ Shri JJT University, Jhunjhunu, Rajasthan, ${ }^{2}$ Sree Siddaganga College of Pharmacy, Tumkur, Karnataka, India
}

\author{
*Corresponding Author: Vijaya Kumar S
}

Email: vijitumkur@rediffmail.com

\begin{abstract}
Teaching learning both takes place simultaneously; teaching can never be effective without an effective learning at the same an effective learning can't take place without effective teaching. Teacher has a very vital role to play in imparting knowledge to the pupils and this is likely to occur only when the teacher is able to acknowledge the necessity of the learner. In nursing education there are many factors that are responsible for the learning process to take place. Hence, it is always the teacher who is responsible for choosing the best and effective method to deliver the best lessons to the students. The aim of this research was to identify the efficacy of lecture cum demonstration on the knowledge and skills of the nursing students regarding cranial nerve assessment. The pre-experimental research design approach was considered appropriate for conducting this study. About 200 nursing students getting education in hand-picked nursing colleges of Lucknow were considered appropriate for this study. The relevant fact was gathered using self-prepared multiple choice knowledge questionnaires and an observation check list to assess the clinical expertise of the students. The lecture cum demonstration was effectual in upgrading the knowledge and clinical expertise of the student nurses.
\end{abstract}

Keywords: Lecture, Demonstration, Knowledge, Skill, Cranial nerve assessment.

\section{Introduction}

Teaching learning process in totality has an impact of the situations in which the complete process takes place. Teaching learning is said to bear fruits and is thought to be long lasting if it is related to the real life situations in totality, teacher always plays a crucial role in imparting the knowledge to the learners and this is possible only when they are able to take into consideration the demand of the learner. An effective teaching can take place only when the teacher understands the need of the learner. ${ }^{1}$

In nursing, the process of learning occurs within a framework of influential factors that affect the character, quality and effectiveness of an educational program of an institution. These influential factors include the institutional philosophy, the administrative policy, the learner, faculty, the classroom environment, the A.V aids that are being used, use of simulators, lab demonstration, types of patients, interests and problems of the community and collective beliefs of those involved in the education program. So while preparing the lessons and while delivering the lecture the teacher has to take into consideration all these factors and only then the teaching will be effective and the goal that has been set will be achieved. ${ }^{2}$

\section{Need for the Study}

Teaching in nursing is a blend of both cognitive and artistic aspects. Teaching skill and technical competency in teaching have effect on the students learning. The first and the foremost principles in education that is important is adopting a teaching method according to the purpose, subject matter and the capability of the learners. ${ }^{3}$ The teaching strategies should be aimed and focused towards improving the storage of the memory, the recall of the memory, cognition and learning. Clinical training is an integral part of the nursing student's education. The clinical preparation of the students provides an opportunity to link theory with practice while caring for patients. The process of lecture cum demonstration involves various steps like planning the subject matter that needs to be taught, presentation of the subject matter by using lecture as well as the demonstration method. The benefit of this technique is that it is economical, time saving, helps the students to concentrate, and involves student engagement. ${ }^{4}$

\section{Objectives of the Study}

1. To construct a tool on cranial nerve assessment.

2. To evaluate the level of knowledge and skill of the B.Sc nursing students on cranial nerve assessment before the teaching.

3. To evaluate the efficacy of lecture cum demonstration on the knowledge and skill regarding cranial nerve assessment.

4. To find out the interrelation between pre-test knowledge and skill score with selected attributed variables.

\section{Materials and Methods}

For achieving the objectives of the study, the 200 nursing students who were getting education in the chosen nursing institutes of Lucknow were carefully chosen using the convenient sampling approach. And the relevant data was gathered using structured multiple choice knowledge questionnaires and the skill was assessed using an observation check list. The facts collected were scrutinized by applying the descriptive and inferential statistics. ${ }^{5,6}$ 


\section{Result}

Table 1: Frequency distribution of students according to pre-test level of knowledge and skill

\begin{tabular}{|l|l|c|c|c|c|}
\hline \multirow{2}{*}{ S. No } & Level of knowledge \& skill & \multicolumn{2}{|c|}{ Knowledge } & \multicolumn{2}{c|}{ Skill } \\
\cline { 2 - 6 } & & $\mathbf{F}$ & $\mathbf{\%}$ & $\mathbf{F}$ & $\mathbf{\%}$ \\
\hline 1 & Inadequate $(<50 \%)$ & 160 & 80.0 & 171 & 85.5 \\
\hline 2 & Fairly adequate $(50-75 \%)$ & 40 & 20.0 & 29 & 14.5 \\
\hline 3 & Adequate $(>75 \%)$ & - & - & - & - \\
\hline Over all & 200 & 100 & 100 & 200 \\
\hline
\end{tabular}

The table shows frequency distribution of the nursing students according to the pre-test level of knowledge and skill regarding cranial nerve assessment. $80 \%$ of the students had inadequate knowledge while $85.5 \%$ had inadequate skill. Similarly $20 \%$ of the students had fairly adequate knowledge while $14.5 \%$ had fairly adequate skill.

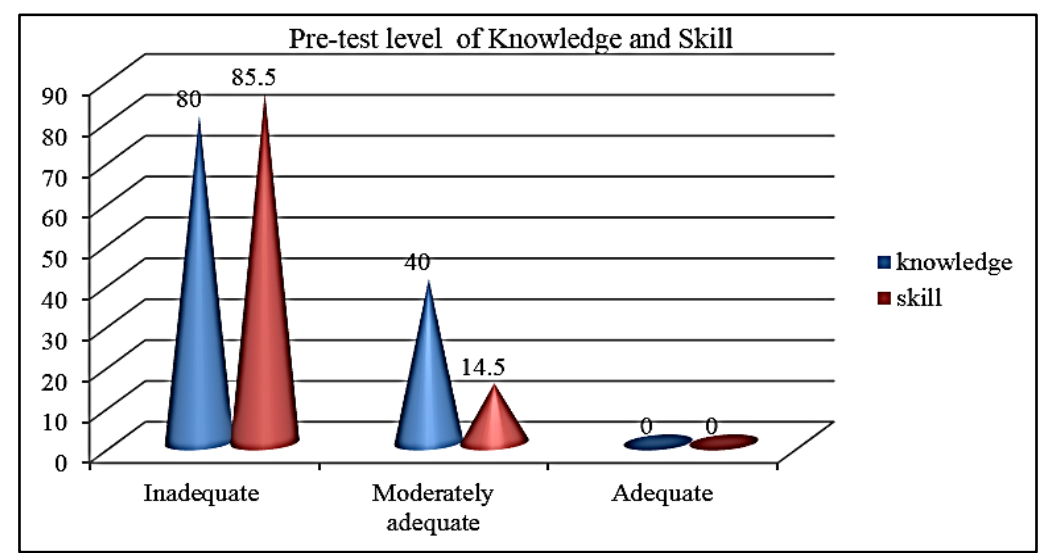

Fig. 1: Graph representing level of pre-test knowledge and skill

Table 2: Frequency distribution of students according to post-test level of knowledge and skill

\begin{tabular}{|l|l|c|c|c|c|}
\hline \multirow{2}{*}{ S. No } & Level of knowledge \& skill & \multicolumn{2}{|c|}{ Knowledge } & \multicolumn{2}{c|}{ Skill } \\
\cline { 2 - 6 } & & F & \% & F & \% \\
\hline 1 & Inadequate $(<50 \%)$ & - & - & 18 & 9.0 \\
\hline 2 & Fairly adequate $(50-75 \%)$ & 151 & 75.5 & 143 & 71.5 \\
\hline 3 & Adequate $(>75 \%)$ & 49 & 24.5 & 39 & 19.5 \\
\hline Over all & 200 & 100 & 200 & 100 \\
\hline
\end{tabular}

The table shows frequency distribution of the nursing students according to the post-test level of knowledge and skill regarding cranial nerve assessment. About $9 \%$ of the students had inadequate skill. $75.5 \%$ of the students had fairly adequate knowledge while $71.5 \%$ had fairly adequate skill. Similarly $24.5 \%$ of the students had adequate knowledge while $19.5 \%$ had adequate skill.

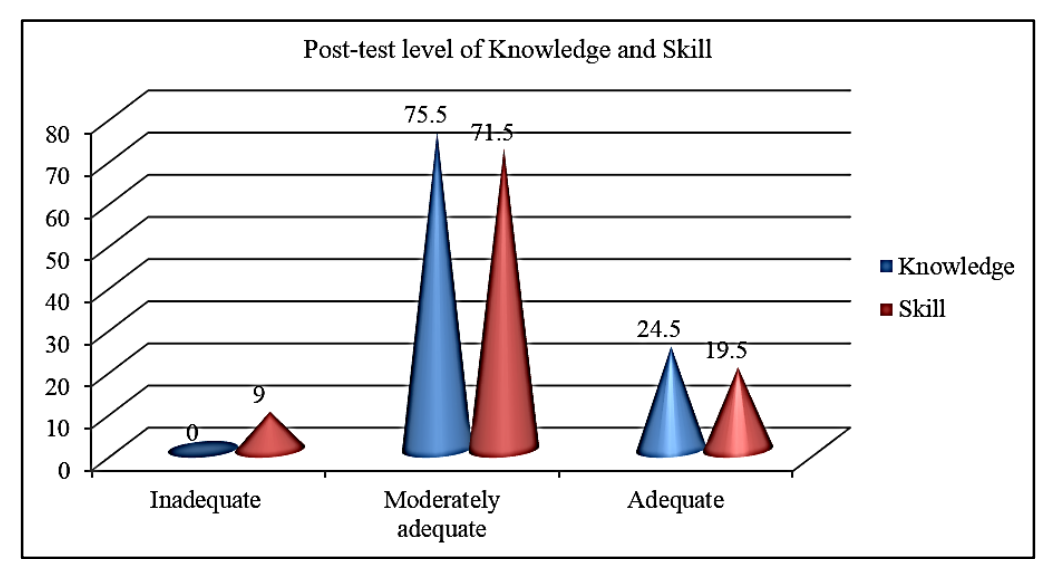

Fig. 2: Graph representing level of post-test knowledge and skill 
Table 3: Effectiveness of lecture cum demonstration on the knowledge and skill of B.Sc. Nursing students. $\mathbf{n}=\mathbf{2 0 0}$

\begin{tabular}{|l|c|c|c|c|c|c|c|}
\hline \multirow{2}{*}{ S. No } & \multirow{2}{*}{ Variable } & \multirow{2}{*}{$\begin{array}{c}\text { Max } \\
\text { score }\end{array}$} & \multicolumn{3}{|l|}{ Paired t-difference (Enhancement) } & \multirow{2}{*}{ t-test value } & \multirow{2}{*}{ P-value } \\
\cline { 3 - 6 } & & & Mean & SD & Mean\% & & \\
\hline 1. & Knowledge & 28 & 7.87 & 2.84 & 28.2 & $12.82^{*}$ & $\mathrm{p}<0.05$ \\
\hline 2 & Skill & 28 & 5.82 & 3.81 & 20.7 & $8.74^{*}$ & $\mathrm{P}<0.05$ \\
\hline
\end{tabular}

*Significant at $\mathrm{p}<0.05$ level, $199 \mathrm{df}$. The paired t-test approaches the Z-test as the sample size large.

The above table presents the effectiveness of lecture cum demonstration which was proved by comparison of pre and post-test knowledge and skill scores. The mean difference of knowledge was 7.87 in between pre and post test knowledge with SD of difference 2.84. And also, the mean score percent of knowledge was $28.2 \%$ (enhancement of knowledge). The paired t-test was found to be statistically significant $(\mathrm{p}<0.05)$. Similarly, the mean difference of skill was 5.82 in between pre and post test skill with SD of difference 3.81. And also, the mean score percent of knowledge was $20.7 \%$ (enhancement of knowledge). The paired t-test was found to be statistically significant $(\mathrm{p}<0.05)$.

\section{Discussion}

Based on the objectives of the study it was observed that the skill score of about 171 students that is $85.5 \%$ had inadequate skills and about 29 of the samples that is $14.5 \%$ had moderately adequate skill while none of them had adequate skill regarding cranial nerve assessment during the pre-test.

The findings are important as it will help to evaluate the difference in the pre-test and post-test grades and help the researcher to identify the achievement of the students and interpret if the study objective has been achieved.

In order to identify the efficacy of the lecture cum demonstration in enhancing the knowledge and skill the pre and post-test score were compared. And on comparison it was found that the mean of the enhanced knowledge was found to be 7.87 with a standard deviation of 2.84 and mean percentage to be $28.2 \%$. The t-test score was 12.82 at 'p' less than 0.05 which proves the efficacy of lecture cum demonstration in enhancing the knowledge of the study subjects.

Similarly for the skill the mean enhancement in the skill was found to be 5.82 with a standard deviation of 3.81 and mean percentage $20.7 \%$. The value of t-test was found to be 8.74 at 'p' less than 0.05 which thereby proves the efficacy of the lecture cum demonstration. Hence based on the findings the fourth objective of the study has been achieved, which proves the efficacy of lecture cum demonstration in enhancing the knowledge and skills of the nursing students.

\section{Nursing Implications}

Nursing Practice: The future of nursing practice lies in the hands of the student nurses, they are the one who are responsible for the nursing care and faster recovery of the patients. The best care can be given only if they have the adequate knowledge about the nursing care. And this knowledge can be imparted to them in a better way by a combination of lecture and demonstration of each procedure. The responsibility lies in the hands of the teacher to assess the performance of the student and plan the teaching accordingly to enhance the knowledge and skills of the nursing students. A well-planned lecture cum demonstration will help to provide good knowledge to the students and enhance their knowledge regarding patient care and prevention of the spread of the disease. ${ }^{6}$

Nursing Administration: Nursing administration deals with implementing the nursing care in the health care set up. As an administrator the nurse has many roles to play and it is possible only when the nurse has adequate knowledge of her various roles. As a nurse manager she has to look after the nursing care of the patient as well promotes staff development. In service education and continuing nursing education should be initiated for nurses to update the knowledge and skills and for this the best teaching method should be used, which should be easily understandable and interesting and attention drawing. Various types of teaching methods with different AV aids can be used such as booklets, pamphlets etc which will help in improving the knowledge and clinical expertise of the scholars and the nurses. $^{7}$

Nursing Education: Nursing education makes it possible for the student as well as the staff nurses to acquire ample information and develop clinical practice in order to fulfil their duties and responsibilities in the nursing field. By implementing the best teaching method we as nurse educator can help the students to keep their knowledge up to date as per the demand of the growing technology and help the students to gather latest information and develop clinical practice with regard to the patient care and prevention of any illness. With the help of a well planned teaching method the teacher can draw the attention of the students towards the subject matter, develop interest in the students and help them gain knowledge and improve their skills. ${ }^{8}$

\section{Nursing Research}

In India, only few research studies have been carried out on the use of varied method of instruction for the up gradation of the knowledge and clinical proficiency of the nursing students. Research in the field of nursing helps to support the nursing profession. All nursing personnel must join hands to provide scientifically tested material or programs to evolve a time bound plan for the up gradation of the knowledge and clinical proficiency of the students which is in pace with the technological advancement and directed towards the best nursing care of the patients. ${ }^{9}$ This 
study revealed that lecture cum demonstration was effective in improving the knowledge and clinical proficiency of the nursing students regarding cranial nerve assessment. ${ }^{10}$

1. A study can be carried out on the teaching and learning material accessible at varied nursing institutes.

2. A study can be performed on the method of instruction being used by the instructors and pupil's contentment.

3. An investigation can be done on the A.V aids available in varied nursing institutes for delivering lecture to the pupils.

4. An investigation can be done on the practical use of AV aids in making learning easy and productive in nursing institutes.

5. An exploratory study can be carried out on the proficiency of the teacher regarding usage of the A.V aids.

\section{Conclusion}

Teaching and learning is a process that goes hand in hand, effective teaching takes place only if there are interested learners and an effective learning occurs only when the teaching is made interesting. One of the methods of teaching in the nursing field is the use of lecture cum demonstration method of teaching. To identify the impact of lecture cum demonstration on the knowledge and clinical expertise of the students this research study was done and it was found that it had an positive impact on the students learning and expertise. Hence we can conclude that lecture cum demonstration is an effective method of imparting education.

\section{References}

1. Mangal S. K, Mangal Uma, 2010, essentials of educational technology, PHI learning private limited, second edition, page 239-250.
2. Latha Bhat, Effectiveness of two Teaching Methods on 'Cranial Nerve Assessment'. International Journal of Nursing Education, 2011;3:65-69.

3. Neeraja K.P, Testbook of nursing education, Jaypee brothers medical publisher (P) ltd, 2003, first edition, page 53-81

4. R. Sudha, 2013, nursing education: principles and concepts, Jaypeebrothers medical publisher (P) ltd, first edition, page 252-257.

5. B T Basvanthappa, Nursing research, Jaypee publishers, Second Edition, Page no: 92-362.

6. Suresh K Sharma and Reena Sharma, "Communication and educational technology in nursing”, 2012, Elsevier publication, Page no 126-357.

7. Nahind Zarifsanaiey, Mitra Amini, Farideh Saadal. A comparison of educational strategies for the acquisition of nursing student's performance and critical thinking: simulation-based training vs. integrated training (simulation and critical thinking strategies). BMC Medical Education, 2016;16:294.

8. Poomarin Intachai. Determining the Effectiveness of Three Teaching Methods for Blood Pressure Measurement Skills, 2014;10(2):46-51

9. Suresh K Sharma, "Nursing research and statistics", Reprint 2012, Elsevier publication, 2012.

10. Kumar M, Saxena I, Kumar J, Kumar G, Kapoor S. Assessment of lecture strategy with different teaching AIDS. Journal of Clinical and Diagnostic Research. 2015;9(1):CC01CC05.

How to cite this article: Pandey A, Vijaya K. S. Evaluate effectiveness of lecture cum demonstration on knowledge and skill regarding cranial nerve assessment among B.Sc. nursing students. J Manag Res Anal. 2018;5(4):393-396. 